\title{
NMDA/glutamate mechanism of anxiolytic-like action of zinc in Vogel conflict test in mice
}

\author{
Mohamed S. Abdel-Maksoud ${ }^{1}$, Medhat I. Abdel-hamid ${ }^{2}$, \\ Yasser M. Moustafa ${ }^{3}$ \\ ${ }^{I}$ Department of Pharmacology \&Toxicology, Faculty of Pharmacy, Sinai University, \\ El-Arish, North Sinai, Egypt. \\ ${ }^{2}$ Department of Pharmacology \& Toxicology, Faculty of Medicine, Al-Azhar University, \\ Nasr City, Cairo, Egypt. \\ ${ }^{3}$ Department of Pharmacology \& Toxicology, Faculty of Pharmacy, Suez Canal University, \\ Ismailia, Egypt.
}

\begin{abstract}
The objective of our study is to investigate the possible anxiolytic-like effect of zinc using one of the most useful animal models of anxiety, which is the Vogel conflict test (VCT) and to investigate the possible involvement of the glutamatergic system and NMDA receptors in this postulated effect. The anxiolytic-like effect of $\mathrm{ZnCl}_{2}(20 \mathrm{mg} / \mathrm{kg}$, i.p. $)$ in the VCT was abolished by the pretreatment of animals with $\mathrm{N}$-methyl-D-Aspartic acid $(75 \mathrm{mg} / \mathrm{kg}$, i.p., NMDA receptor agonist) that per se produced no effect in VCT. Moreover, the treatment of mice with CGP37849 $(0.3 \mathrm{mg} / \mathrm{kg}$, i.p., a competitive NMDA receptor antagonist) or MK-801 (0.05 mg/kg, i.p., a non-competitive NMDA receptor antagonist) was able to potentiate the action of sub-effective dose of $\mathrm{ZnCl}_{2}(10 \mathrm{mg} / \mathrm{kg}$, i.p.). Overall results indicate that zinc induces the anxiolytic-like effect in mice without development of tolerance and inhibition of the NMDA receptor activity is involved in the mechanism of this effect.
\end{abstract}

Keywords-Anxiety, Glutamate, NMDA receptor, Vogel conflict test, Zinc.

\section{INTRODUCTION}

Zinc is the second most abundant transition element in the body. It essential for life and regulate the function of numerous structural, transcriptional, and enzymatic proteins [1,2].Zinc has three functions in zinc enzymes: catalytic, coactive (or cocatalytic) and structural [3,4].Because zinc is necessary for DNA replication, transcription and protein synthesis, this metal powerfully influences cell division and differentiation $[5,6]$.Thus, dietary zinc deprivation retards the growth of humans and animals $[7,8]$.

The CNS contains a large amount of Zn, but it's not evenly distributed throughout the brain and intriguingly $\mathrm{Zn}$-containing neurons are found in areas known to be important in depression and anxiety including cerebral cortical regions, hippocampus, most amygdaloid nuclei, and the lateral septum [1].

The zinc concentration in the brain increases with growth after birth and is maintained constant in the adult brain [9].Approximately $90 \%$ of the total brain zinc is zinc metalloproteins [10].The rest is in the presynaptic vesicles. Vesicular zinc, play a role in synaptic neurotransmission in the mammalian brain and serve as an endogenous neuromodulator of several important receptors including the $\gamma$-amino butyric acid (GABA) and $N$-methyl-D-aspartate (NMDA) receptors [11-13]. A substantial fraction of zinc in brain is located inside synaptic vesicles of glutamatergic terminals in chelatable forms and released with intense neuronal activity in a calcium-dependent manner [14].

It has been reported that neuropsychological behavior such as anxiety and aggression is increased in zinc-deficient rats and mice [15-18]. Zinc-deficient mice also displayed anxiety-related behavior in the novelty suppressed feeding test (most common anxiety-based test) measured as enhanced latencies to eat. Rats fed on a zinc-deficient diet also exhibit anxiety-like behavior [18]. This data indicated that zinc deficiency may contribute to the development of anxiety and the experimentally induced zinc deficiency might be a useful model of anxiety.

The NMDA receptor is a ligand-gated ion channel [19] and has a number of regulatory sites that are targets for modulation by endogenous and exogenous compounds. The regulatory sites include a binding site for the main endogenous agonist glutamate, a high-affinity binding site at which glycine acts to allow glutamateinduced channel opening and sites within the ionophore where MK-801 and ketamine bind and produce a voltage-dependent open channel blocking. 
Several studies indicated that NMDA receptor antagonists are effective in animal models of depression and tests that predict antidepressant activity in humans. Recently, the antidepressant-like properties of functional antagonists of the glutamatergic-NMDA receptor have been demonstrated [20]. Besides antidepressant-like effects, the NMDA receptor antagonists exhibit anxiolytic-like activity, examined in the elevated plus-maze test [21-25].Thus; antidepressant- and anxiolytic-like properties of NMDA receptor antagonists suggest the involvement of glutamatergic system in the mechanism of antidepressant and anxiolytic actions [25].

Zinc is an inhibitor of the NMDA receptor (Ionotropic glutamate receptor) [11,13], and it was found that zinc can down regulate glutamate response by reducing the ability of glutamate to activate post-synaptic NMDA receptors by direct inhibition of these receptors. Hence, in present study we test the hypothesis that zinc exerts anxiolytic effect in one of the most used tests of anxiety, Vogel Conflict Test (VCT) by inhibiting the NMDA receptor.

\section{EXPERIMENTAL PROCEDURES}

\subsection{Animals and their Environments}

The investigations were carried out using healthy adult male $B A L B / c$ mice with a weight of 20-30 grams, supplied by the Modern Veterinary Office for Laboratory Animals (Cairo, Egypt). Mice were housed in groups of 10 per cage in well ventilated opaque polypropylene cages $(30 \times 25 \times 13 \mathrm{~cm}$ ). Cage substrate (wood shavings) was changed three times weekly. Food (standard pellet diet) and tap water ad libitum were added daily. Animals were maintained at $21 \pm 2{ }^{\circ} \mathrm{C}$ and constant relative humidity under $12: 12 \mathrm{~h}$ light and dark cycle (lights on at 8:00 a.m.).

Animals were allowed to acclimatize under the standard housing conditions for 2 weeks prior to use. All animals were naive to drug treatment and experimentation at the beginning of the study. All experiments were conducted at the light phase of the light/dark cycle between 10:00 a.m. and 4:00 p.m. to eliminate circadian influence on animal behavior. All experimental protocols were approved by the Institutional Animal Care and Use Committee at the Faculty of Pharmacy, Suez Canal University, Ismailia, Egypt.

\subsection{Drugs and Materials}

Diazepam, Zinc chloride, N-methyl-D-aspartic acid (NMDA), DL-/E/-amino-4-methyl-5-phosphono3-pentenoic acid (CGP 37849) and 15R,10S)-(+)-5-methyl-10,11-dihydro-5H dibenzo[a,d]cyclohepten-5,10imine hydrogen maleate (MK- 801) were used in this study and all were supplied from Sigma Aldrich Co., Germany, Except diazepam was supplied from Amoun Co., Egypt. All drugs were dissolved in $0.9 \%$ normal saline, and were administered intraperitonealy (i.p.) in a volume of $10 \mathrm{ml} / \mathrm{kg}$.

\subsection{Drugs administration}

\subsubsection{Acute Administration}

Zinc chloride was always administered i.p. 30 minutes before the behavioral test. In case of drug combinations, the first drug is administered i.p. 30 minutes before the second one, 30 minutes later animals were subjected to the test. Doses of zinc refer to pure zinc ions. Control animals received an i.p. injection of saline (vehicle) at respective times. All drugs were administered in a volume of $10 \mathrm{ml} / \mathrm{kg}$.

\subsubsection{Chronic Administration}

For testing the tolerance to the predicted effect, zinc is administrated chronically 14 times in 24-hrs intervals, last administration 24 hrs before the test. Control animals received an i.p. injection of saline (vehicle) at respective times. The volume of vehicles or drug solutions administrated was $10 \mathrm{ml} / \mathrm{kg}$.

\subsection{Vogel conflict test (VCT)}

This test was a modification of that described by Vogel et al. (1971) [26] and recently used by Mathiasen and Mirza (2005) [27]. The test cage $(14.5 \times 16 \times 16 \mathrm{~cm})$ was made from glass and had a metal grid floor. The spout of an externally mounted water bottle protruded into the experimental cage, and was positioned in the centre of one wall and $2.5 \mathrm{~cm}$ above the grid floor. This spout was connected to the shocker (LE 100-25 Vogel Shocker, Panlab, Cornellá, Spain). After every 20 licks, the animal received a 0.5 miliAmpere shock for 2 sec. that was delivered through the metallic grid floor. The total number of licks and shocks delivered during the testing session was measured using PACKWIN v2.0.01 software (Panlab, Cornellá, Spain). The whole apparatus was located inside a quiet dim testing room. Testing sessions were conducted during the early light phase of the light/dark cycle.

Procedure: Mice were deprived of water for $48 \mathrm{hrs}$ before the test. After the first $24 \mathrm{hrs}$ of water deprivation, they were allowed to drink freely for 3 minutes in the test cage in order to locate the spout of drinking bottle (habituation session). Animals that could not find the spout were excluded from the experiment. After the next $24 \mathrm{hrs}$ of water deprivation, mice received various i.p. drug treatments. Thirty minutes following i.p. injection of drugs, each mouse was individually subjected to the test cage to drink water. During a testing 
period of 3 minutes, an animal received a 0.5 miliAmpere shock after every 20 licks. The number of licks and shocks delivered were registered and the increased number of shocks taken per 3 minutes was considered as an index of lowered anxiety-like behavior (anxiolytic effect). Mice were habituated to the testing room undisturbed for at least $2 \mathrm{hrs}$ before habituation and testing sessions.

\subsection{Statistical Analysis}

Data were expressed as mean \pm standard error of mean (S.E.M.) and were analyzed using one-way analysis of variance (ANOVA) followed by Bonferroni's post hoc test for multiple comparisons. Simple t-test was used for comparison between two groups only. All statistical analyses were done using the Statistical Package for Social Sciences, version 17 (SPSS Inc., Chicago, IL, USA). Differences were considered significant at $P<0.05$.

\section{RESULTS}

\subsection{Effect of systemic administration of diazepam on anxiety-like behavior of mice tested in the VCT}

Statistical analysis with simple t-test indicated that systemic administration of the clinically used diazepam (3 mg/kg, i.p.) induced an anxiolytic-like effect in mice tested in the VCT, as it significantly increased the number of shocks taken per 3 minutes compared to the control group [P $<0.001]$. Fig. (1).

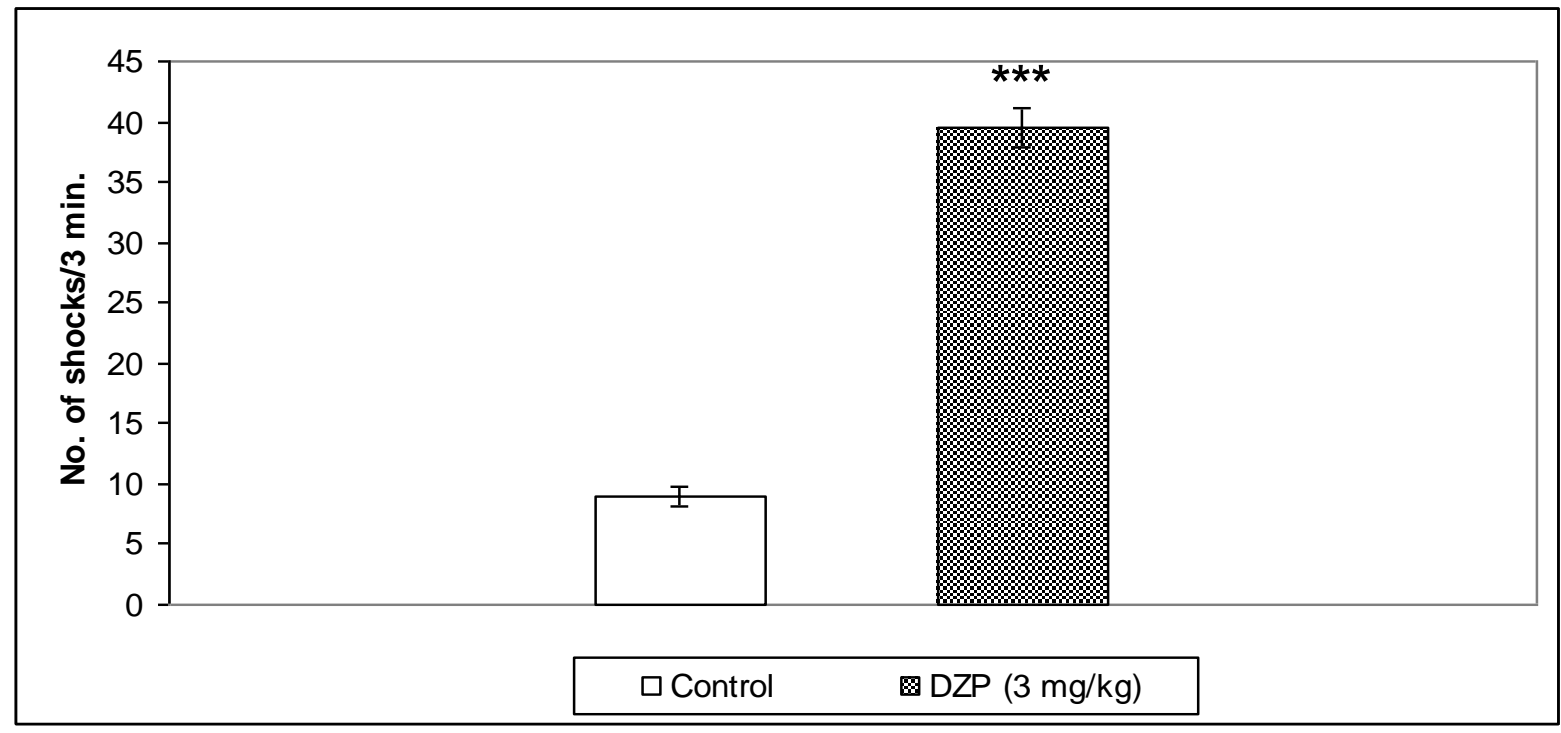

Fig. (1). Effect of systemic administration of diazepam (3 mg/kg, i.p.) on the number of shocks taken per $3 \mathrm{~min}$. by mice tested in VCT. Diazepam was administered $30 \mathrm{~min}$. before the test in a volume of $10 \mathrm{ml} / \mathrm{kg}$. Each column represents the mean value \pm S.E.M. (simple t-test), ${ }^{* * *} p<0.001$ vs. control group; $n=8-10$ per group.

\subsection{Effect of systemic administration of zinc at different dose levels on anxiety-like behavior of mice tested in the VCT}

Statistical analysis with one-way ANOVA indicated that systemic administration of zinc induced an anxiolytic-like effect as it significantly increased the number of shocks taken per 3 minutes in mice tested in the $\operatorname{VCT}\left[\mathrm{F}_{(3,26)}=16.80, \mathrm{P}<0.001\right]$.

Post hoc test revealed that zinc at 20 and $30 \mathrm{mg} / \mathrm{kg}$, i.p. caused a significant increase in the number of shocks taken per 3 minutes, while the dose of $10 \mathrm{mg} / \mathrm{kg}$, i.p. showed no significant anxiolytic-like effect compared to the control group. Fig. (2). 


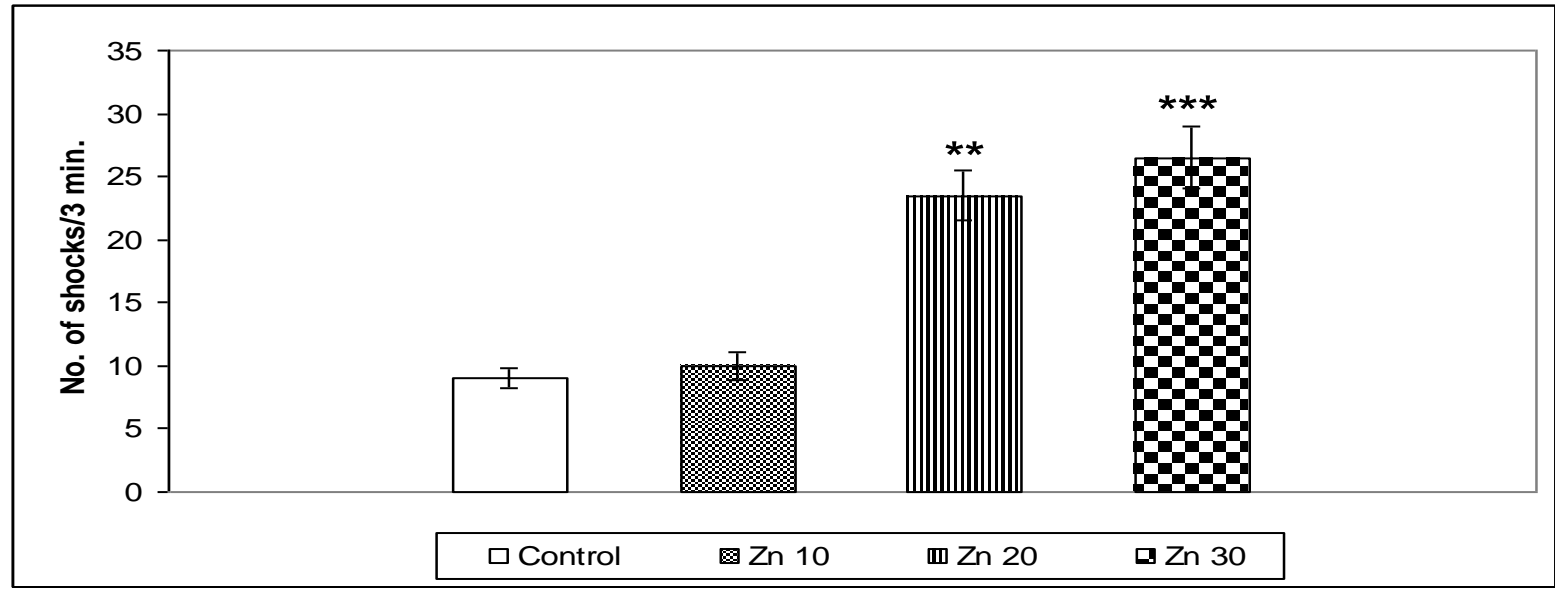

Fig. (2). Effect of systemic zinc administration at different doses on the number of shocks taken per 3 min. by mice tested in VCT. Zinc was administered $30 \mathrm{~min}$. before the test in a volume of $10 \mathrm{ml} / \mathrm{kg}$. Each column represents the mean value \pm S.E.M. (one-way ANOVA followed by Bonferroni's post hoc test), $* * p<0.01$ and $* * * \mathrm{p}<0.001$ vs. control group; $\mathrm{n}=8-10$ per group.

\subsection{Effect of systemic pretreatment with the NMDA receptor agonist NMDA, upon the effect of zinc on anxiety-like behavior of mice tested in the VCT}

Statistical analysis with one-way ANOVA revealed that systemic pretreatment with N-methyl-Daspartic acid (NMDA), a competitive NMDA receptor agonist (75 mg/kg, i.p.) significantly abolished the anxiolytic-like effect of Zinc $(20 \mathrm{mg} / \mathrm{kg}$, i.p.) on the number of shocks taken per 3 minutes by mice tested in the $\operatorname{VCT}\left[\mathrm{F}_{(3,23)}=6.847, P<0.001\right]$.

Post hoc test demonstrated that NMDA $(75 \mathrm{mg} / \mathrm{kg}$, i.p.) significantly reduced the number of shocks of Zinc (20 mg/kg, i.p.) compared to zinc per se effect. However, NMDA (75 mg/kg, i.p.) per se had no significant effect on the number of shocks compared to the double vehicle treated group (control group). Fig. (3).

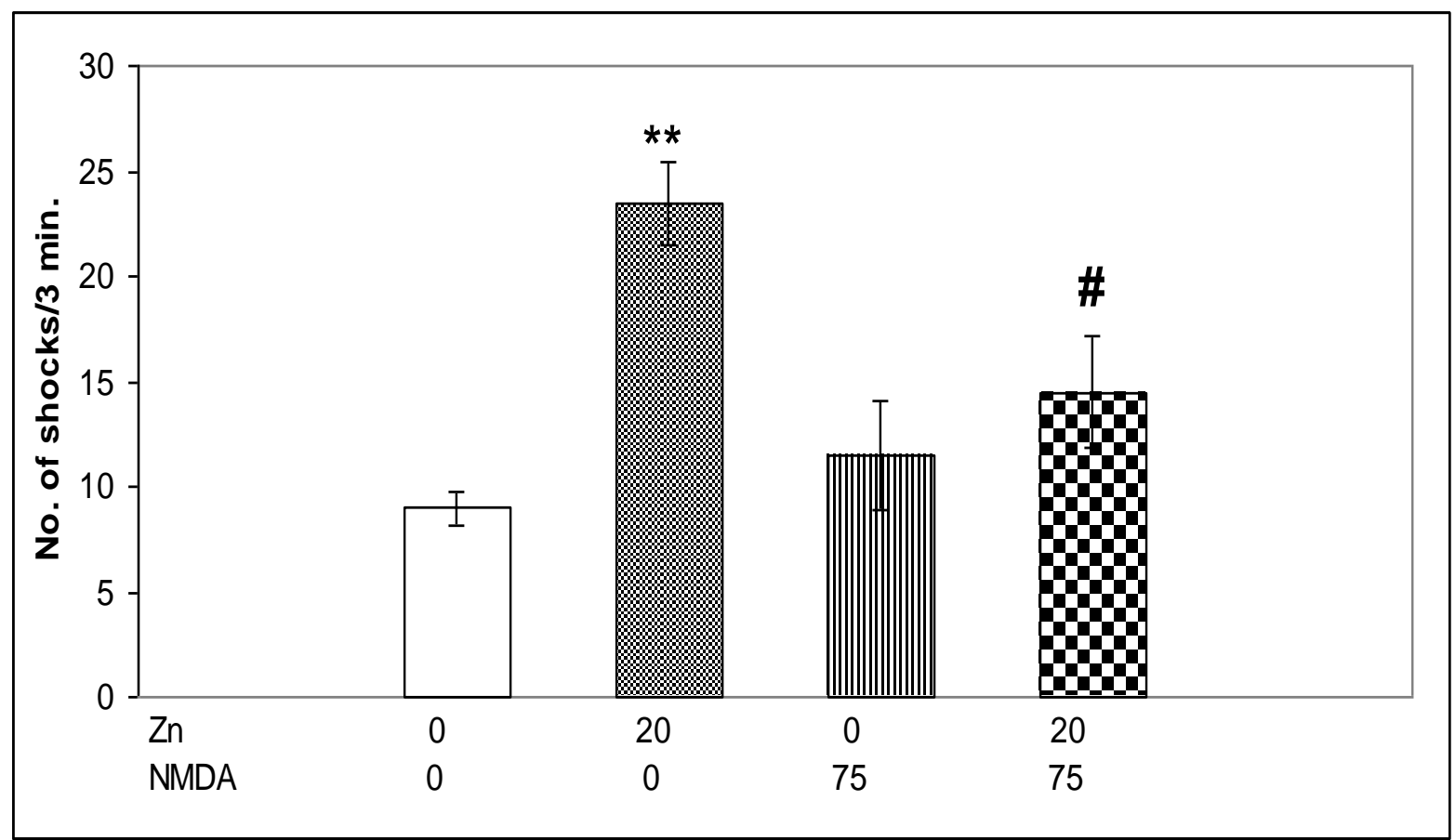

Fig. (3). Effect of combined administration of zinc and NMDA on the number of shocks taken per 3 min. by mice tested in VCT. Zinc (20 mg/kg, i.p.) was administered $30 \mathrm{~min}$. before the test, and NMDA (75 mg/kg, i.p.) $30 \mathrm{~min}$. before zinc administration, both in a volume of $10 \mathrm{ml} / \mathrm{kg}$. Each column represents the mean value \pm S.E.M. (one-way ANOVA followed by Bonferroni's post hoc test). **p $<0.01$ vs. control group; \# p $<0.05$ vs. $\mathrm{Zn}(20 \mathrm{mg} / \mathrm{kg})$ treated group; $\mathrm{n}=8-10$ per group. 


\subsection{Effect of administration of different types of NMDA receptor antagonists at different dose levels on} anxiety-like behavior of mice tested in the VCT

The effects of systemic administration of CGP 37849 (a competitive NMDA receptor antagonist) and MK-801 (a noncompetitive NMDA receptor antagonist) on anxiety-like behavior of mice tested in VCT are shown in Fig. (4). Statistical analysis with one-way ANOVA indicated that systemic administration of both antagonists induced an anxiolytic-like effect as they significantly increased the number of shocks taken per 3 minute $\left[\mathrm{F}_{(4,33)}=8.816, \mathrm{p}<0.001\right]$.

Post hoc test revealed that CGP 37849 given at the dose of $0.6 \mathrm{mg} / \mathrm{kg}$, i.p. significantly increased the number of shocks taken $(\mathrm{p}<0.05)$ but at the dose of $0.3 \mathrm{mg} / \mathrm{kg}$, i.p. was ineffective, while MK-801 given at the dose of $0.1 \mathrm{mg} / \mathrm{kg}$, i.p. also significantly increased the number of shocks $(\mathrm{p}<0.05)$ but at the dose of $0.05 \mathrm{mg} / \mathrm{kg}$, i.p. was ineffective. All compared to the control group.

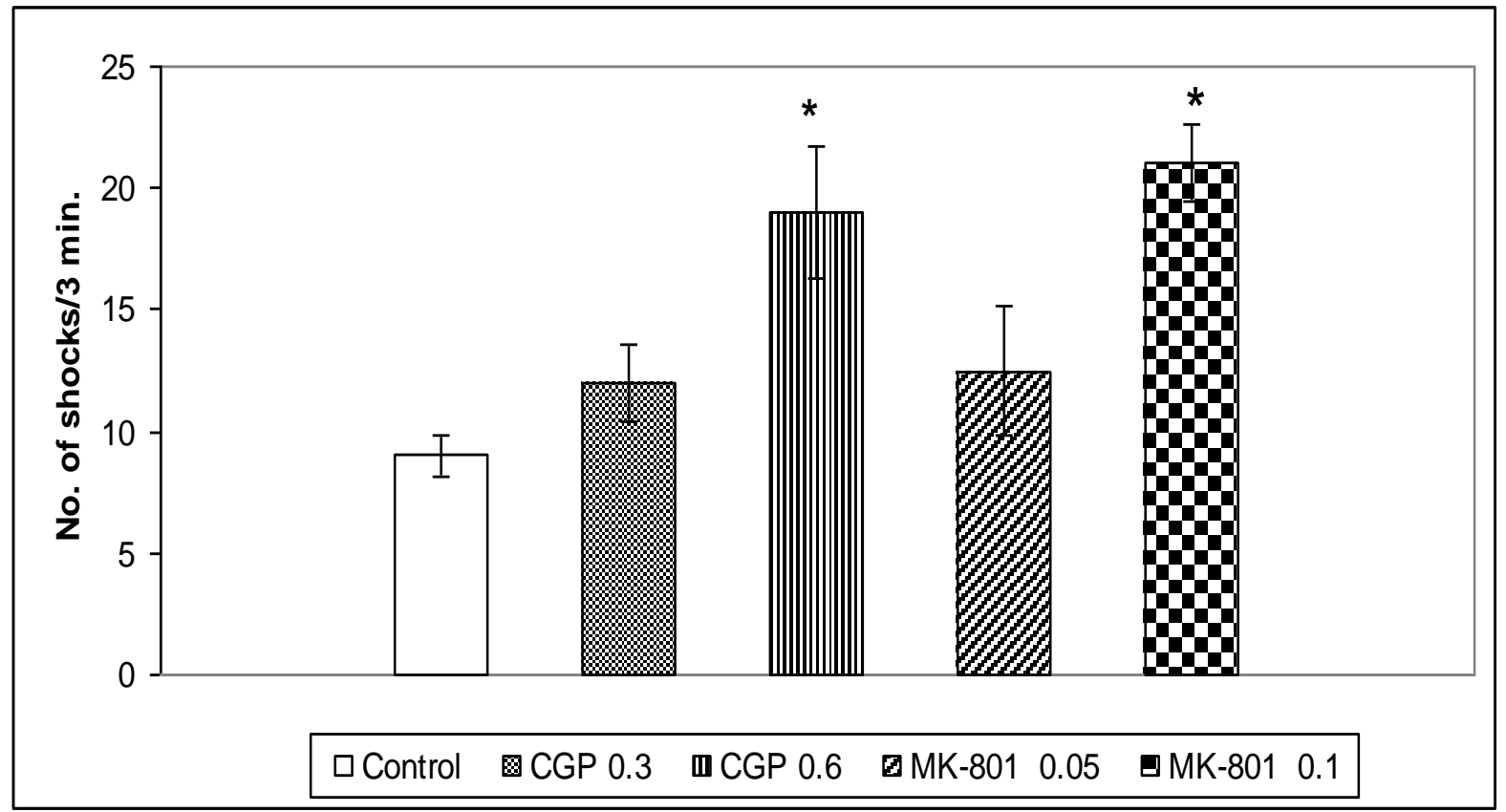

Fig. (4). Effect of administration of CGP 37849 and MK-801 at different doses on the number of shocks taken per $3 \mathrm{~min}$. by mice tested in VCT. Each was administered $30 \mathrm{~min}$. before the test in a volume of $10 \mathrm{ml} / \mathrm{kg}$. Each column represents the mean value \pm S.E.M. (one-way ANOVA followed by Bonferroni's post hoc test). ${ }^{*} \mathrm{p}<$ 0.05 vs. control group; $n=8-10$ per group.

\subsection{Effect of combined administration of sub-effective doses of zinc and CGP 37849 on anxiety-like behavior of mice tested in the VCT}

The effect of combined administration of zinc and CGP 37849 at their sub-effective dose levels on anxiety-like behavior of mice tested in VCT are shown in Fig. (5). Statistical analysis with one-way ANOVA indicated that combined administration of sub-effective dose of zinc $(10 \mathrm{mg} / \mathrm{kg}$, i.p.) with the like dose of CGP $37849(0.3 \mathrm{mg} / \mathrm{kg}$, i.p. $)$ induced an anxiolytic-like effect as it significantly increased the number of shocks taken per 3 minute $\left[\mathrm{F}_{(3,51)}=6.886, \mathrm{p}<0.01\right]$.

Post hoc test demonstrated that zinc given alone at the dose of $10 \mathrm{mg} / \mathrm{kg}$, i.p. had no effect on number of shocks taken, Also CGP 37849 given alone at the dose of $0.3 \mathrm{mg} / \mathrm{kg}$, i.p. was ineffective. While the combined administration of zinc (10 mg/kg, i.p.) with CGP $37849(0.3 \mathrm{mg} / \mathrm{kg}$, i.p.) significantly increased the number of shocks compared to their per se effects $(\mathrm{p}<0.05)$ and to the control group $(\mathrm{p}<0.01)$. 


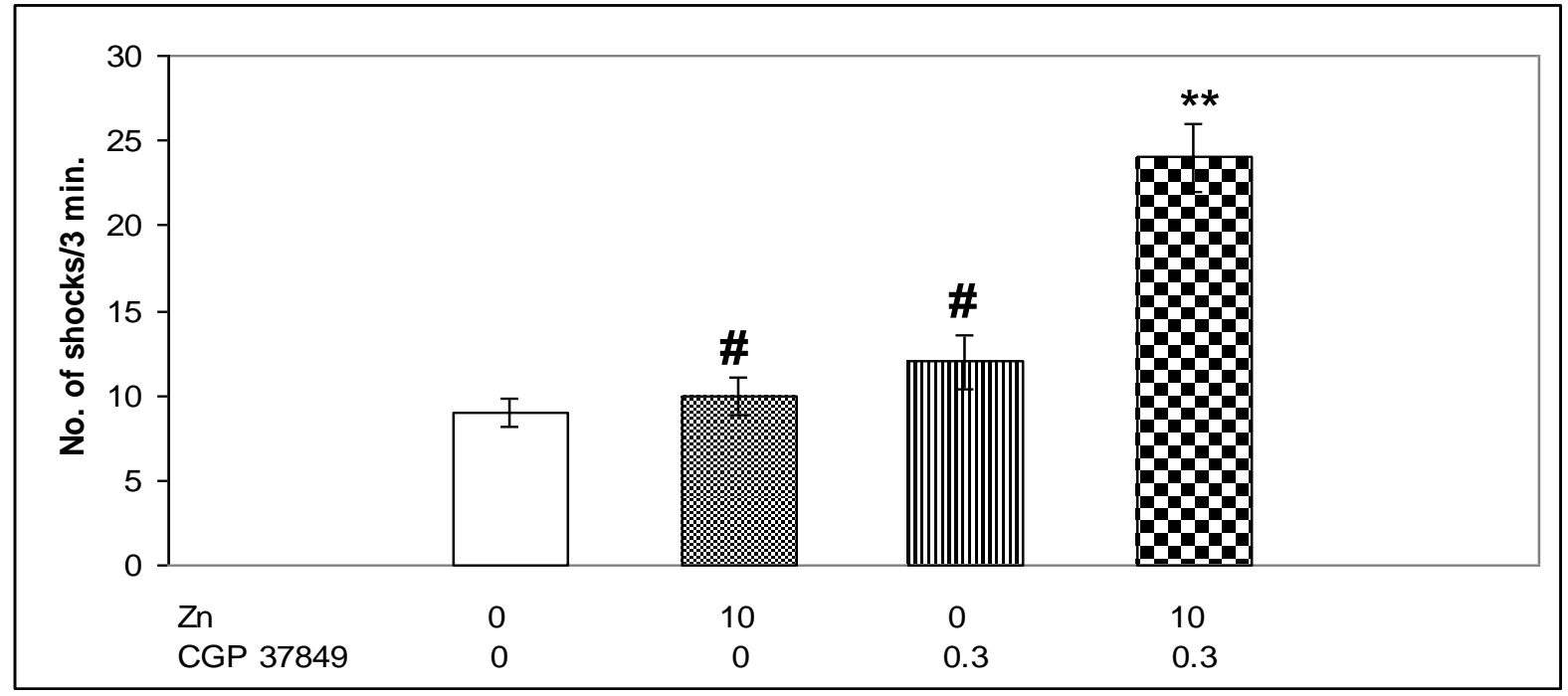

Fig. (5). Effect of combined administration of zinc and CGP 37849 on the number of shocks taken per 3 min. by mice tested in VCT. Zinc (10 mg/kg, i.p.) was administered $30 \mathrm{~min}$. before the test, and CGP $37849(0.3 \mathrm{mg} / \mathrm{kg}$, i.p.) $30 \mathrm{~min}$. before zinc administration, both in a volume of $10 \mathrm{ml} / \mathrm{kg}$. Each column represents the mean value \pm S.E.M. (one-way ANOVA followed by Bonferroni's post hoc test). ${ }^{*} \mathrm{p}<0.01$ vs. control group; \# $\mathrm{p}<0.05$ vs. $(\mathrm{Zn}+\mathrm{CGP} 37849)$ group; $\mathrm{n}=8-10$ per group.

\subsection{Effect of combined administration of sub-effective doses of zinc and MK-801 on anxiety-like behavior of mice tested in the $V C T$}

The effect of combined administration of zinc and MK-801 at their sub-effective dose levels on anxiety-like behavior of mice tested in VCT is shown in Fig. (6). Statistical analysis with one-way ANOVA indicated that combined administration of sub-effective dose of zinc $(10 \mathrm{mg} / \mathrm{kg}$, i.p.) with the like dose of MK$801(0.05 \mathrm{mg} / \mathrm{kg}$, i.p.) induced an anxiolytic-like effect as it significantly increased the number of shocks taken per 3 minute $\left[\mathrm{F}_{(3,20)}=9.847, \mathrm{p}<0.001\right]$.

Post hoc test demonstrated that zinc given alone at the dose of $10 \mathrm{mg} / \mathrm{kg}$, i.p. had no effect on number of shocks taken, Also MK-801 given alone at the dose of $0.05 \mathrm{mg} / \mathrm{kg}$, i.p. was ineffective. While the combined administration of zinc (10 mg/kg, i.p.) with MK-801 (0.05 mg/kg, i.p.) significantly increased number of shocks compared to their per se effects $(\mathrm{p}<0.05)$ and to the control group $(\mathrm{p}<0.01)$.

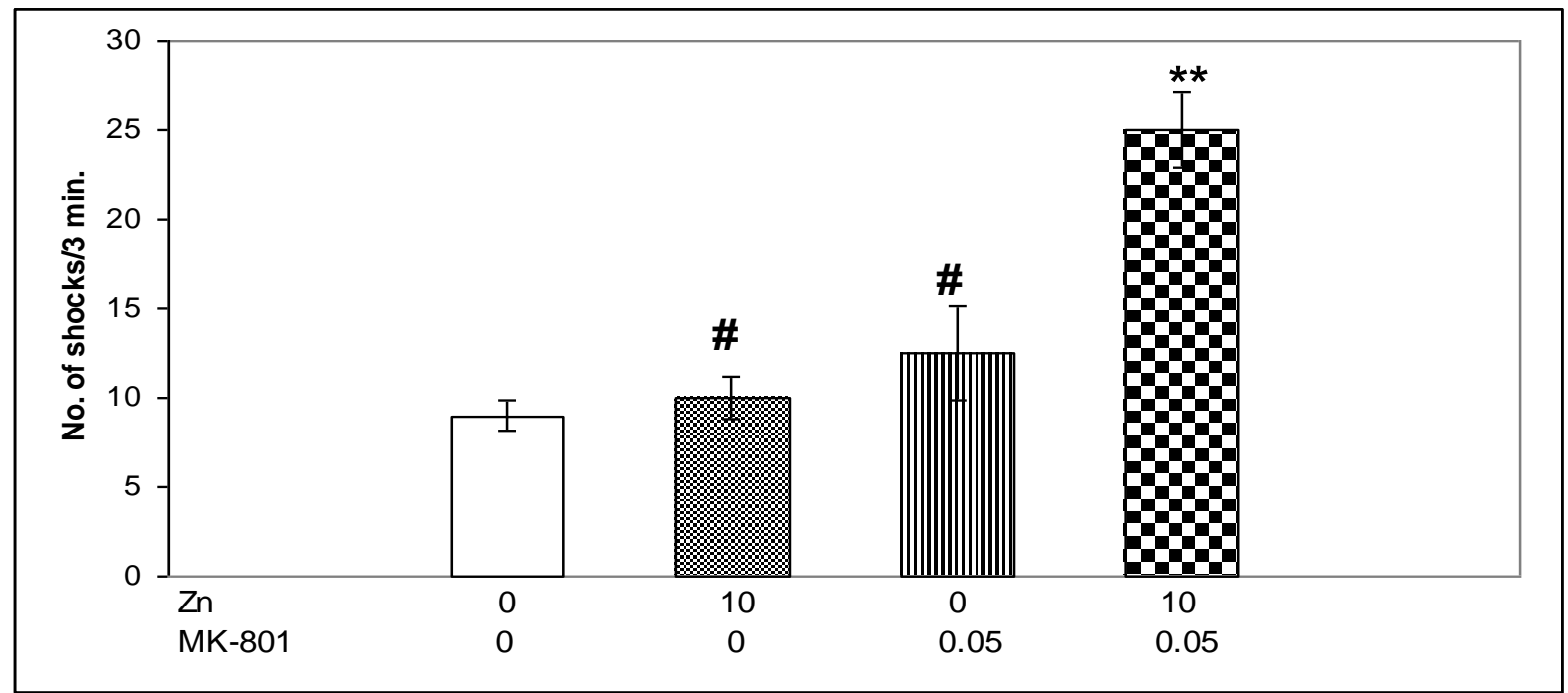

Fig. (6). Effect of combined administration of zinc and MK-801 on the number of shocks taken per 3 min. by mice tested in VCT. Zinc $(10 \mathrm{mg} / \mathrm{kg}$, i.p.) was administered $30 \mathrm{~min}$. before the test, and MK-801 $(0.05 \mathrm{mg} / \mathrm{kg}$, i.p.) $30 \mathrm{~min}$. before zinc administration, both in a volume of $10 \mathrm{ml} / \mathrm{kg}$. Each column represents the mean value \pm S.E.M. (one-way ANOVA followed by Bonferroni's post hoc test). ** $p<0.01$ vs. control group; \# $p<0.05$ vs. (MK-801+Zn) group; $\mathrm{n}=8-10$ per group. 


\subsection{Effect of chronic zinc administration on anxiety-like behavior of mice tested in the VCT}

The effects of chronic treatment with zinc at lowest effective dose $(20 \mathrm{mg} / \mathrm{kg}$, i.p.) on anxiety-like behavior of mice tested in VCT are shown in Fig. (7).Statistical analysis with simple t-test indicated that chronic systemic administration of zinc similarly to the acute administration significantly induced an anxiolytic-like effect as it significantly increased the number of shocks taken per 3 minutes compared to the control group $[\mathrm{p}<0.001]$.

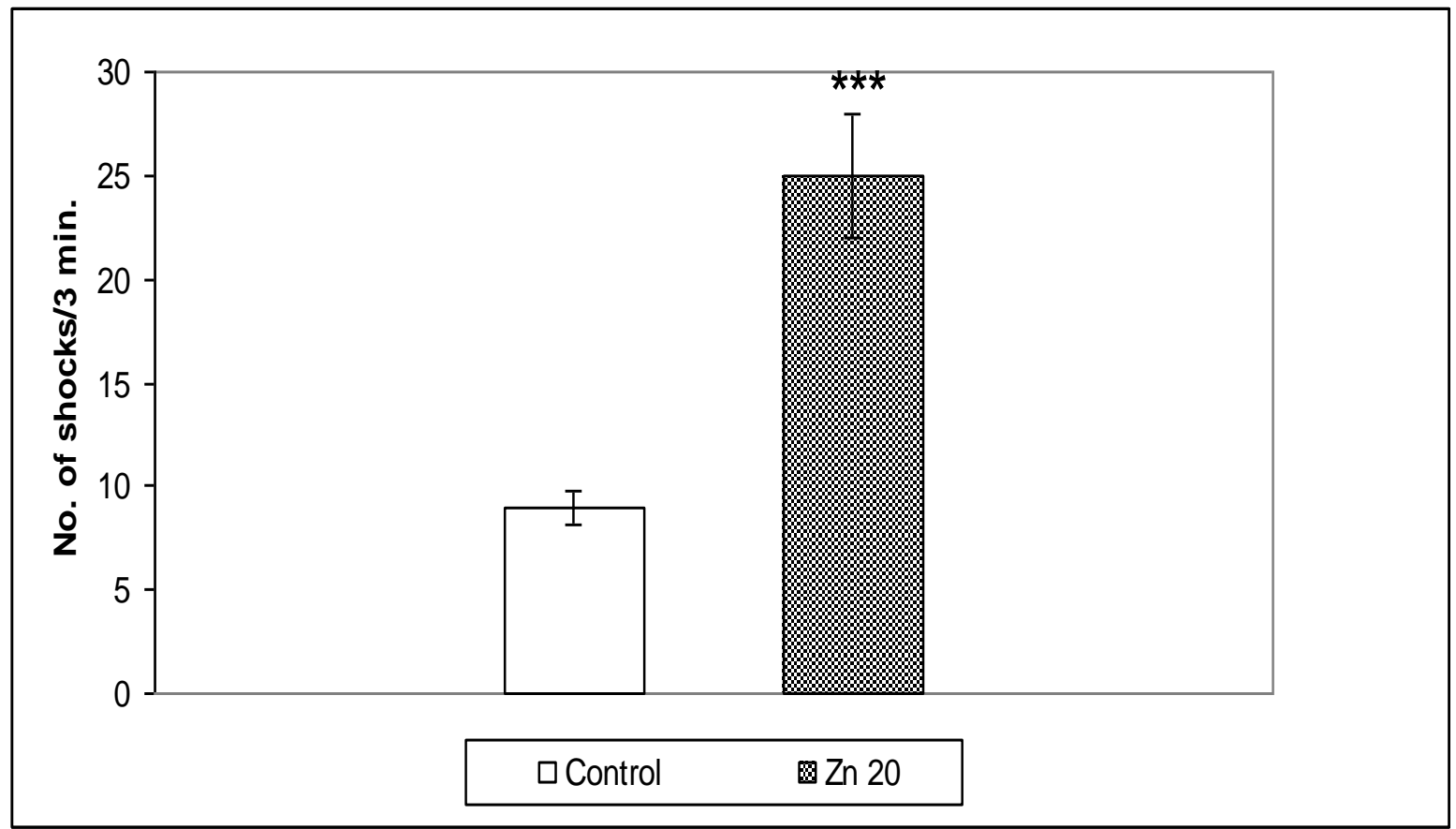

Fig. (7). Effect of chronic zinc administration at dose $20 \mathrm{mg} / \mathrm{kg}$, i.p. on the number of shocks taken per $3 \mathrm{~min}$. by mice tested in VCT. Zinc and saline were administered chronically (14 times, last administration $24 \mathrm{hrs}$ before the test). Each column represents the mean value \pm S.E.M. (Simple t-test), $* * * p<0.001$ vs. control group; $\mathrm{n}=8-10$ per group.

\section{DISCUSSION}

Affective disorders (anxiety and depression) are recurrent and life threatening mental illness with high morbidity and mortality. The World Health Organization estimates that affective disorders are now the fourth most important cause worldwide of loss in human disability adjusted life years, and predicts that they will be the second by the year 2020 .

Data from biochemical and neuroimaging studies indicate that the modulation of normal and pathologic anxiety and depression states is associated with multiple regions in the brain and abnormal function in several neurotransmitter systems, including Norepinephrine (NE), $\gamma$-Aminobutyric acid (GABA), Glutamate and serotonin (5-HT). Theses systems have been the target of current pharmacological treatments for affective disorders including benzodiazepines, tricyclic antidepressants, monoamine oxidase inhibitors and selective serotonin reuptake inhibitors. These treatments are effective in only $60-70 \%$ of patients and produce a variety of unwanted side effects [28].Thus the search for "better" anxiolytics has been in progress for decades and recently researchers focus their attention on the glutamate receptors (mainly the NMDA receptor complex) $[20,25,29,30]$.

Experiments described in this study showed that competitive NMDA receptor antagonist CGP 37849 had an anxiolytic-like action in mice measured in Vogel conflict test. CGP 37849 significantly increased the number of shocks in VCT at the dose $(0.6 \mathrm{mg} / \mathrm{kg}$, i.p.) which is in line with previously published data [21,31].

Similarly, experiments described in this study showed that non-competitive NMDA receptor antagonist MK-801 (MK-801 blocks the neurophysiologic effects of the NMDA receptor complex by binding to a site in the ion channel of the receptor, thereby blocking the channel for cations [32]) had an anxiolytic-like action in mice measured in Vogel conflict test. MK-801 significantly increased the number of shocks in VCT at the dose $(0.1 \mathrm{mg} / \mathrm{kg}$, i.p.) which is in line with previously published data [21,31].All these results indicate that inhibition 
of the NMDA receptor activity by either competitive or non-competitive antagonists is involved in the mechanism of anxiolytic activity.

Also, the present study is the first demonstration of the anxiolytic-like activity of zinc using VCT. The results showed that zinc significantly increased the number of shocks taken per 3 minutes by mice tested in VCT at doses 20 and $30 \mathrm{mg} / \mathrm{kg}$,i.p. without affecting the motor activity, while $10 \mathrm{mg} / \mathrm{kg}$,i.p. was ineffective, and this effect was comparable with that observed with diazepam (the reference drug).

Besides the investigation of anxiolytic effect of zinc, our study aimed to investigate the possible mechanism of this effect and the involvement of NMDA/glutamate system in this mechanism. Therefore, in the present study we evaluate the effect of CGP 37849 (the competitive NMDA receptor antagonist) on the anxiolytic-like activity of zinc and we chose the dose of $0.3 \mathrm{mg} / \mathrm{kg}$, i.p. of CGP 37849 , which by itself was ineffective in VCT. The combined administration of this low dose of CGP 37849 with the ineffective dose of zinc $(10 \mathrm{mg} / \mathrm{kg}$, i.p.) significantly increased the anxiolytic parameter (the number of shocks taken per $3 \mathrm{~min}$.). Thus, the combined treatment of zinc and competitive NMDA receptor antagonist produced a synergistic anxiolytic-like effect in the VCT in mice.

Similarly, to evaluate the effect of MK-801 (the non-competitive NMDA receptor antagonist) on the anxiolytic-like activity of zinc we chose the dose of $0.05 \mathrm{mg} / \mathrm{kg}$, i.p. of MK- 801 which by itself was ineffective in VCT. The combined administration of this low dose of MK-801 with the ineffective dose of zinc $(10 \mathrm{mg} / \mathrm{kg}$, i.p.) significantly increased the anxiolytic parameter. Thus, the combined treatment of zinc and non-competitive NMDA receptor antagonist produced a synergistic anxiolytic-like effect in the VCT in mice.

Recently Poleszak et al., [33] demonstrated that activation of the NMDA receptor by N-methyl-Daspartic acid (NMDA) counteracted the NMDA receptor antagonists-induced antidepressant-like activity in the forced swimming test (FST). In our study the anxiolytic-like activity of zinc was also antagonized by NMDA given at dose $75 \mathrm{mg} / \mathrm{kg}$, i.p.

All these results indicate that zinc behaved as typical NMDA antagonist and further support the notion that inhibition of the NMDA receptor activity is involved in the mechanism of anxiolytic activity of zinc.

As we know, treatment of anxiety and depression in humans requires chronic (weeks) administration of drugs for manifestation of the therapeutic effect [34], thus, the neuronal adaptive alterations seem to participate in mechanisms of action of anxiolytic \& antidepressants. For this reason, it is important to examine if tolerance to the acute antidepressant-like effect develops after prolonged treatment with an antidepressant agent. Development of tolerance is also an important factor in anxiolytic activity [25].

Our data demonstrate that chronic treatment with anxiolytic dose of zinc $(20 \mathrm{mg} / \mathrm{kg}$, i.p.) does not alter the measured behavioral response to zinc challenge 24-hrs after the last dose. These results indicate that zinc induces the anxiolytic-like effect in animals without development of tolerance to these actions, which strongly suggests a potential anxiolytic activity of zinc in this disorder in humans.

Finally we can summarize all previous data as zinc is effective in producing an anxiolytic effect in mice without development of tolerance or affecting the locomotor activity of the animals, and these activities are done by acting as NMDA receptor antagonist.

It may be speculated that zinc supplementation could enhance antidepressant and anxiolytic therapy in human. Such supplementation by zinc could allow to lower the effective doses of drugs, the unwanted side effects could be diminished and the cost of the therapy reduced. The clinical evaluation of such assumption is required.

\section{CONCLUSION}

The present results indicate that zinc is effective in producing an anxiolytic-like effect in the VCT when administered by i.p. route and without development of tolerance to this action. Also zinc can produce a synergistic effect with different types of NMDA receptor antagonists at their sub effective doses. This suggests that zinc behaved as typical NMDA antagonist and further support the notion that inhibition of the NMDA receptor activity is involved in the mechanism of anxiolytic activity of zinc.

\section{REFERENCES}

[1]. C.E. Brown, R.H. Dyck, Distribution of zincergic neurons in the mouse forebrain, J Comp Neurol, 479, 2004, 156-167.

[2]. C.J. Frederickson, S.W. Suh, D. Silva, C.J. Frederickson, R.B. Thompson, Importance of zinc in the central nervous system: the zinc-containing neuron. $J$ Nutr 130, 2000, 1471S-1483S.

[3]. B.L. Vallee, D.S. Auld, Active zinc binding sites of zinc metalloenzymes, in: H. Birkedal-Hansen, Z. Werb, H. Welgus, H.V. Wart (Eds.), Matrix Metalloproteinases and Inhibitors. Matrix Supplement 1 (Stuttgart, Fischer, 1992) 5.

[4]. B.L. Vallee, K.H. Falchuk, The biological basis of zinc physiology, Physiol. Rev. 73, 1993, 79-118.

[5]. J.E. Coleman, Zinc proteins: enzymes, storage proteins, transcription factors, and replication proteins, Annu. Rev. Biochem, 61, 1992, 897-946. 
[6]. B.L. Vallee, K.H. Falchuk, Zinc and gene expression, Biol. Sci. 294, 1981, 85-197.

[7]. A.S. Prasad, Clinical, biochemical and nutritional spectrum of zinc deficiency in human subjects: an update, Nutr. Rev, 41, 1983, 197-208.

[8]. A.S. Prasad, Clinical spectrum and diagnostic aspects of human zinc deficiency, in A.S. Prasad (Ed.), Essential and Toxic Trace Elements in Human Health and Disease (New York, Liss, 1988) 3-53.

[9]. W.R. Markesbery, W.D. Ehmann, M. Alauddin, T.I.M. Hossain, Brain trace element concentrations in aging, Neurobiol. Aging, 5, 1984, 19-28.

[10]. C.J. Frederickson, Neurobiology of zinc and zinc-containing neurons, Int. Rev. Neurobiol. 31, 1989, 145-238.

[11]. N.L. Harrison, S.J. Gibbons, $\mathrm{Zn}^{+2}$ : an endogenous modulator of ligand- and voltage-gated ion channels. Neuropharmacology, 33, 1994, 935-952.

[12]. E.P. Huang, Metal ions and synaptic transmission: think zinc, Proc. Natl. Acad. Sci. 94, 1997, 13386-13387.

[13]. T.G. Smart, X. Xie, B.J. Krishek, Modulation of inhibitory and excitatory amino acid receptor ion channels by zinc. Prog Neurobiol 42, 1994, 393-441.

[14]. Y.H. Ahn, Y.H. Kim, S.H. Hong, J.Y. Koh, Depletion of intracellular zinc induces protein synthesis-dependent neuronal apoptosis in mouse cortical culture, Exp Neurol, 154, 1998, 47-56.

[15]. Y. Chu, M.F. Mouat, R.B. Harris, J.A. Coffield, A. Grider, Water maze performance and changes in serum corticosterone levels in zinc-deprived and pair-fed rats. Physiol. Behav, 78, 2003, 569-578.

[16]. A. Takeda, H. Tamano, F. Kan, H. Itoh, N. Oku, Anxiety-like behavior of young rats after 2-week zinc deprivation. Behav.Brain Res.12, 2007, 1-6.

[17]. A. Takeda, H. Tamano, F. Kan, T. Hanajima, K. Yamada, N. Oku, Enhancement of social isolation-induced aggressive behavior of young mice by zinc deficiency. Life Sci. 82, 2008a, 909-914.

[18]. N.M. Tassabehji, R.S. Corniola, A. Alshingiti, C.W. Levenson, Zinc deficiency induces depression-like symptoms in adult rats. Physiol Behav 95, 2008, 365-369.

[19]. W. Danysz, C. Parsons, Glycine and N-methyl-D-aspartate receptors: Physiological significance and possible therapeutic applications. Pharmacol. Rev. 50, 1998, 597-664.

[20]. P. Skolnick, R.T. Layer, P. Popik, G. Nowak, I.A. Paul, R. Trullas, Adaptation of N-methyl-d-aspartate (NMDA) receptors following antidepressant treatment: implications for the pharmacotherapy of depression, Pharmacopsychiatry, 29, 1996, 23-26.

[21]. R.W. Dunn, R. Corbett, S. Fielding, Effects of 5-HT $\mathrm{HA}_{\mathrm{A}}$ receptor agonists and NMDA receptor antagonists in the social interaction test and the elevated plus maze. Eur J Pharmacol, 169, 1989, 1-10.

[22]. A. Plaz'nik, W. Palejko, M. Nazar, M. Jessa, Effects of antagonists at the NMDA receptor complex in two models of anxiety. Eur Neuropsychopharmacol, 4, 1994, 503 - 512.

[23]. J.L. Wiley, A.F. Cristello, R.L. Balster, Effects of site-selective NMDA receptor antagonists in an elevated plusmaze model of anxiety in mice. Eur J Pharmacol 294, 1995, 101-107.

[24]. E. Przegalin'ski, E. Tatarczyn'ska, A. Dere-WesoClek, E. Chojnacka-Wo’jcik, Anticonflict effects of a competitive NMDA receptor antagonist and a partial agonist at strychnine-insensitive glycine receptors. Pharmacol Biochem Behav 54, 1996, 73 -77.

[25]. A. Pilc, A. Klodzinska, G. Nowak, A role for glutamate in the treatment of anxiety and depression: focus on group I metabotropic glutamate (mGlu) receptors, Drugs Fut. 27, 2002, 753-763.

[26]. J.R. Vogel, B. Beer, D.E. Clody, A simple and reliable conflict procedure for testing antianxiety agents. Psychopharmacology 21, 1971, 1-7.

[27]. L. Mathiasen, N.R. Mirza, A comparison of chlordiazepoxide, bretazenil, L838,417 and zolpidem in a validated mouse Vogel conflict test. Psychopharmacol (Berl), 182, 2005, 475-484.

[28]. L.E. Hollister, J.G. Csernansky, Clinical pharmacology of psychotherapeutic drugs. $3^{\text {rd }}$ ed., (New York, Churchill Livingstone, 1990).

[29]. P. Skolnick, Antidepressants for the new millennium, Eur. J. Pharmacol. 375, 1999, 31-40.

[30]. P. Skolnick, B. Legutko, X. Li, F.B. Bymaster, Current perspectives on the development of non-biogenic aminebased antidepressants, Pharmacol. Res. 43, 2001, 411-423.

[31]. M. Karcz-Kubicha, M. Jessa, M. Nazar, A. Plaznik, S. Hartmann, C.G. Parsons, Anxiolytic activity of glycine-B antagonists and partial agonists - no relation to intrinsic activity in the patch. Neuropsychopharmacology, 36, 1997, 1355-1367.

[32]. E.H.F. Wong, J.A. Kemp, T. Priestley, A.R. Knight, G.N. Woodruff, L.L. Iversen, The anticonvulsant MK-801 is a potent N-methyl-D-aspartate-antagonist. Proc Natl Acad Sci 83, 1986, 7104-7108.

[33]. E. Poleszak, P. Wlaź, A. Wróbel, M. Dybała, M. Sowa, S. Fidecka, A. Pilc, G. Nowak, Activation of the NMDA/glutamate receptor complex antagonizes the NMDA antagonists'-induced antidepressant-like effects in forced swim test. Pharmacol Rep, (in press).

[34]. I. Oswald, V. Brezinova, D.L.F. Dunleavy, On the slowness of action of tricyclic antidepressant drugs. $\mathrm{Br} J$ Psychiatry, 120, 1972, 673-7. 